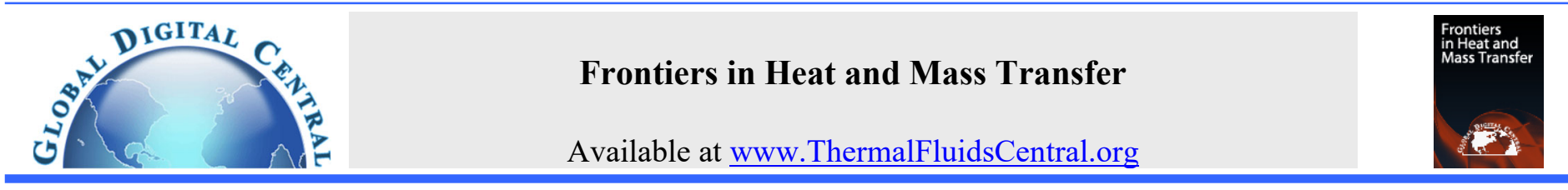

\title{
THIN THERMAL MANAGEMENT MODULES USING FLATTENED HEAT PIPES AND PIEZOELECTRIC FANS FOR ELECTRONIC DEVICES
} \author{
Akbarzadeh $^{\mathrm{c}}$ \\ ${ }^{a}$ Fujikura Ltd, 1-5-1, Kiba, Koto-ku, Tokyo 135-8512, Japan \\ ${ }^{b}$ The Heat Pipes, 1022, Shiohama 1-4-33, Koto-ku, 135-0043, Japan \\ ${ }^{c}$ RMIT University, Bundoora, Victoria, Australia
}

Jason Velardo ${ }^{\mathrm{a}}$, Randeep Singh ${ }^{\mathrm{a},{ }^{*},}$, Mohammad Shahed Ahamed ${ }^{\mathrm{a}}$, Masataka Mochizuki ${ }^{\mathrm{b}}$, Abhijit Date ${ }^{\mathrm{c}}$, Aliakbar

\begin{abstract}
Thermal solutions play an integral role in managing heat loads for electronic devices. As these electronics become more compact and portable, improved thermal management solutions need to be introduced. Thin flattened heat pipes $(0.8 \mathrm{~mm}-2.0 \mathrm{~mm}$ thick $)$ and piezoelectric fans $(1 \mathrm{~mm}$ thick) have been proposed here for this purpose. The maximum heat carrying capacity of the flattened heat pipe was experimentally determined and found to be a function of the flattened heat pipe thickness. Reductions from $48 \mathrm{~W}$ at $2.0 \mathrm{~mm}$ to $7 \mathrm{~W}$ at $0.8 \mathrm{~mm}$ were observed. This was expected to be due to capillary limitations. The piezoelectric fan could be operated in both high flow and high velocity modes. The maximum flow rate and velocity measured was $28 \mathrm{~L} / \mathrm{min}$ and $7.5 \mathrm{~m} / \mathrm{s}$, respectively, for each of these operating modes. Finally, a range of thin thermal modules using these technologies were proposed and some performance metrics were provided. These modules had thickness ranging from 1-6mm and could transfer heat loads of 3$68 \mathrm{~W}$. Thus, flattened heat pipes and piezoelectric fans are promising design components whose utilization can form high performance yet thin thermal management solutions for the next generation of electronic devices.
\end{abstract}

Keywords: Flat heat pipe, piezoelectric fan, electronic cooling, thin thermal module

\section{INTRODUCTION}

The electronic industry is trending towards miniaturization of devices while at the same time extending the capabilities of these devices which requires increased processing power. These advancements lead to large heat generation densities which are thermally challenging to maintain (Mochizuki and Nguyen, 2019). The cooling technology used needs to follow these developments in order to address space constraints and heat removal capacity. If not, operating temperatures will elevate and this can lead to reduced reliability and performance (Mochizuki et al., 2007; McGlen et al., 2004). Portable electronic devices in particular require very compact thermal systems which can remove heat from processing components (ICs such as the CPU or GPU) with the least thermal resistance (Mochizuki et al., 2011).

Thermal management systems for most portable electronic devices typically include three components; the local heat spreader, heat transfer device and heat dissipation (or removal) device. Each of these components can take on different forms and types. A typical system may involve a copper heat spreader, copper-water heat pipe and finned heat sink with fan. This has been shown in Fig. 1.

Two-phase heat transfer devices such as heat pipes have been widely used for electronic thermal management systems for many years, with other two phase devices such as loop heat pipes and vapor chambers being more recently introduced. These devices are useful since their performance exceeds that of solid metals and are lightweight with passive operation.

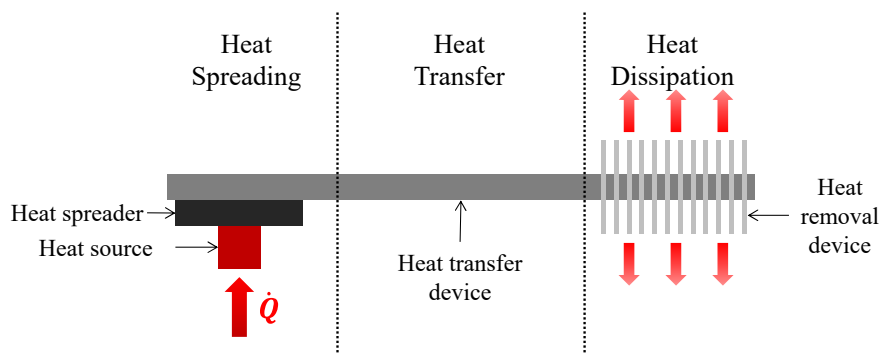

Fig. 1 A typical thermal management system for portable electronic devices consists of heat spreading, heat transfer and heat dissipation components.

Kim et al. (2003) compared heat pipe based thermal management systems for desktop electronics to solid metal heat sinks. The heat pipe systems were found to outperform solid metal systems at lower fan speeds which made them appropriate for low noise applications. The mass of the heat pipe systems was half that of the solid metal system, despite having greater fin surface areas. Wang et al. (2007) investigated the performance of a heat sink embedded with two heat pipes for desktop electronics. The proportion of heat which transferred through the heat pipes compared to the total heat load was studied. It was found that the heat pipes transferred about $35 \%$ of the total heat load and each heat pipe had a maximum heat carrying capacity of about $30 \mathrm{~W}$ before performance degraded. In general, the heat pipe heat sink outperformed the solid metal heat sink. 
Liang and Hung (2010) optimized the ratio of the evaporator length to condenser length of a heat pipe heat sink. The optimum ratio was analytically found to be a function of the heat pipe diameter and condenser fin spacing. Choi et al. (2012) developed a new heat pipe heat sink for low noise electronic cooling applications based on an existing design. The new design varied the heat pipe location and shape as well as the fin and fan arrangement. It had lower noise levels and could maintain lower heat source temperatures at the same heat input as the existing design.

Li et al. (2013) proposed a loop heat pipe for high power LED applications. Such system showed unstable operation at low heat loads and stable operation in the heat load range which could be expected of high power LEDs. The authors stated that the loop heat pipe system had less weight than other passive thermal management systems with the same level of temperature control. Xiao et al. (2017) proposed a heat pipe heat sink for high powered LEDs. It had two heat pipes and was actively cooled by a PWM fan with control system. The control system could manage the operating temperature of the LED and required $2 \mathrm{~W}$ input power. The authors numerically investigated the effect of number of heat pipes and fin pitch on the heat sink performance.

As the industry moves further towards portability and slimmer designs for electronic devices, it requires high performance, low weight, low noise, and thin thermal management solutions to be introduced. Such systems could involve the use of flattened heat pipes and piezoelectric fans. The use of thin/ultra-thin heat pipes has been problematic for several reasons including manufacturing difficulties, performance limitations and cost. They have great potential due to their passive operation and the excellent heat transfer capabilities common to heat pipes. Piezoelectric cooling devices are not highly valued for cooling purposes, thus are seldom used in the electronic industry. Further attention should be given to these since they are solid state devices that produce efficient, reliable, low noise and thin fans.

Nguyen et al. (2000) described some of the earlier use of flattened heat pipes for desktop and portable electronic applications. The flattened heat pipes had thickness of greater than $2 \mathrm{~mm}$. For portable applications, three heat pipe solutions were suggested which included a hinged system, remote heat exchanger system and heat spreader system. The limits of the passive and active systems were $10 \mathrm{~W}$ and $20 \mathrm{~W}$, respectively. Yoo et al. (2000) studied different arrangements of flapping type piezoelectric fans at $60 \mathrm{~Hz}$ and $110 \mathrm{~V}$ or $220 \mathrm{~V}$. The piezoelectric ceramic material PZT5 was used for the actuator with various metals trialed for the blade. The blade material which produced the highest flow was phosphor bronze, although aluminum also performed well given its low cost.

Açikalin et al. (2004) investigated the effect of flapping type piezoelectric fan orientation for LED cooling. Perpendicular and parallel cases (relative to the heat source) were trialed with the perpendicular case generally outperforming parallel. In the perpendicular case, the heat transfer coefficient was found to be $80 \mathrm{~W} / \mathrm{m}^{2} \mathrm{~K}$ which was 3.5 times larger than the natural convection case. This led to reductions in heat source temperatures by over $37{ }^{\circ} \mathrm{C}$. Tao et al. (2008) analyzed the thermal characteristics of flattened heat pipes with axial groove wick structures. The original heat pipe was $6 \mathrm{~mm}$ diameter and was consequently flattened to $3.5 \mathrm{~mm}, 3 \mathrm{~mm}, 2.5 \mathrm{~mm}$ and $2 \mathrm{~mm}$. The thermal performance of the $3.5 \mathrm{~mm}, 3 \mathrm{~mm}$ and $2.5 \mathrm{~mm}$ heat pipes was very similar to that of the $6 \mathrm{~mm}$ diameter heat pipe. However, the performance of the $2 \mathrm{~mm}$ heat pipe was significantly worse than the others; the authors suggested this was due to increased vapor pressure losses. The maximum heat transfer capacity was also reduced from $55 \mathrm{~W}$ to $17.5 \mathrm{~W}\left(50^{\circ} \mathrm{C}\right.$ vapor temperature) between these extremes.

Petroski et al. (2009) proposed an embedded piezoelectric fan heat sink for electronic cooling. As the piezoelectric fan was built into the heat sink, the total volume of the heat sink was unchanged by the fan. The heat sink fin design was also optimized for the fan flow. The embedded heat sink had five times greater performance than a similarly sized extruded metal heat sink. Lu et al. (2011) proposed a flat heat pipe for LED application with maximum heat load of $3 \mathrm{~W}$. The thickness of the flat heat pipe was $5 \mathrm{~mm}$. The experimentally measured thermal resistance, temperature uniformity and transient response were reported. Further, the effects of fill ratio and heat pipe orientation on thermal performance were explored.

Lin and Wong (2013) tested the performance of flattened heat pipes with different wick structures. The wicks used were sintered powder or grooved structures. The original heat pipe had diameter of $6 \mathrm{~mm}$ and was flattened to thickness of $3 \mathrm{~mm}$ and $2.5 \mathrm{~mm}$. Doing so reduced the maximum heat carrying capacity for the sintered powder heat pipe from $25 \mathrm{~W}$ ( $6 \mathrm{~mm}$ diameter) to $20 \mathrm{~W}$ (3mm thickness) to $10 \mathrm{~W}(2.5 \mathrm{~mm}$ thickness). For the grooved heat pipe, this capacity was reduced from $27.5 \mathrm{~W}(6 \mathrm{~mm}$ diameter) to $15 \mathrm{~W}(3 \mathrm{~mm}$ thickness) to $12.5 \mathrm{~W}(2.5 \mathrm{~mm}$ thickness). The cause of these reductions was due to flooding of the condenser for the sintered powder heat pipe and interfacial shear at the liquid-vapor interface for the grooved heat pipe. Li et al. (2015) investigated the thermal performance of flattened heat pipes with sintered powder wick structures. The original heat pipe had diameter of $6 \mathrm{~mm}$ and was flattened to $1.5 \mathrm{~mm}, 1.2 \mathrm{~mm}$ and $1.0 \mathrm{~mm}$. The maximum heat carrying capacity reduced from $25 \mathrm{~W}(1.5 \mathrm{~mm}$ thickness) to $10 \mathrm{~W}(1.0 \mathrm{~mm}$ thickness). The effect of wick thickness and powder particle size was also explored, but the influence of these factors was minimal compared to flattened thickness. An analytical model of evaporation and condensation was also proposed. The condensation model showed moderate agreement whereas the evaporation model had quite poor agreement with experimental results.

Li et al. (2013) explored the thermal performance of flapping type piezoelectric fans for cooling of a plate fin heat sink. The effect of piezoelectric fan configuration and location, as well as the heat sink dimensions was explored. Particle image velocimetry was also used to obtain the flow field produced by the piezoelectric fan. Zhou et al. (2016) developed a thin loop heat pipe for thermal management of portable electronic devices. The solution was passively cooled and had maximum thickness of $1.2 \mathrm{~mm}$. The start-up behavior of the device was stable at $2 \mathrm{~W}$ and a maximum heat load of $12 \mathrm{~W}$ was tested. The effect of device orientation was also explored. Zhou et al. (2017) developed ultra-thin flattened heat pipes with thickness and width of $0.8 \mathrm{~mm}$ and $2.7 \mathrm{~mm}$, respectively. These were originally $2 \mathrm{~mm}$ in outside diameter and used both copper foam and copper mesh as wick structures. They found that $100 \%$ fill had the best performance over a range of heat loads and that a maximum load of $5 \mathrm{~W}$ could be carried by these ultra-thin flattened heat pipes. Han et al. (2018) proposed a flat heat pipe heat sink for cooling scenarios with multiple heat sources. This actively cooled heat sink had 4 flat heat pipes with thickness of $4 \mathrm{~mm}$ each. The performance of this system was strongly affected by which heat sources were active during operation, as well as device orientation.

In this work, experiments have been undertaken to assess the performance of thin and ultra-thin flattened heat pipes and piezoelectric fans. In particular, the effect on heat pipe performance of the flattening procedure used to produce these heat pipes has been analyzed. Thereafter, some thin thermal management solutions based on these devices, within total thickness in the range of $1-6 \mathrm{~mm}$, have been proposed and discussed in the context of electronic systems.

\section{PRINCIPLES OF THIN THERMAL TECHNOLOGY}

Heat pipes are two phase heat transfer devices which operate on continuous evaporation-condensation cycles. Heat is input into the evaporator section which causes the working fluid to evaporate. The vapor travels to the condenser section where it condenses back into a liquid. The liquid is drawn back to the evaporator by capillary action of the wick. This is summarized in Fig. 2. The phase change process can transfer large amounts of heat with small temperature drops which is responsible for the excellent capabilities of the heat pipe. 


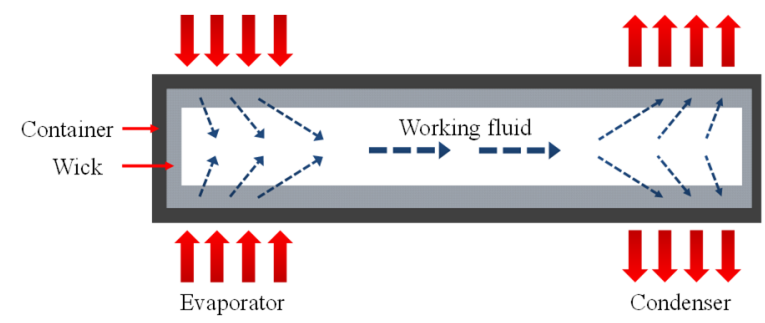

Fig. 2 A cross section of a typical heat pipe showing the operating principle.

Piezoelectric fans operate on the piezoelectric effect whereby a material deforms under an applied alternating current (Hales and Jiang, 2018). The deforming element (actuator) typically has an extended blade attached to it since the deformation is very small. The blade displaces back and forth in a flapping motion as the current alternates (and the actuator simultaneously deforms) producing airflow. A representation of this has been shown in Fig. 3. This type of fan differs to a typical DC fan which produces air flow by the rotational motion of a blade.

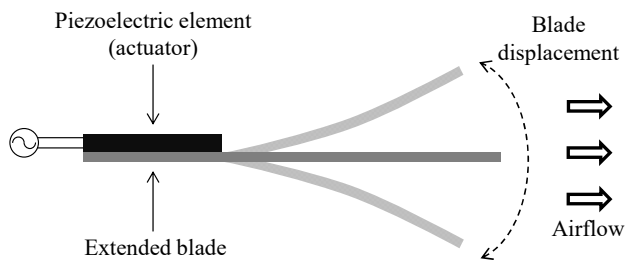

Fig. 3 The operating principle of the flapping type piezoelectric fan.

Here an alternative to the flapping type fan was used. A "bellows" piezoelectric fan was designed which relied on multiple piezoelectric elements and blades in the arrangement as shown in Fig. 4. This arrangement can also be referred to as a double bladed piezoelectric fan.

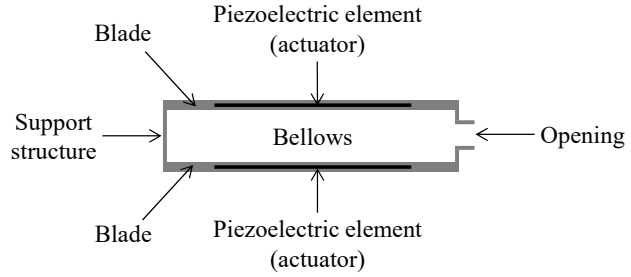

Fig. 4 The bellows type piezoelectric fan - also known as double bladed piezoelectric fan - is an alternative to the single bladed flapping type piezoelectric fan.

The control signal for each piezoelectric actuator was such that each blade would simultaneously displace in opposite directions. This formed expansion and contraction cycles of the bellows and produced airflow as shown in Fig. 5. The piezoelectric devices produced from these technologies have been further discussed in section 3 . The thin thermal management modules based on these devices for compact electronics are introduced in section 6 .
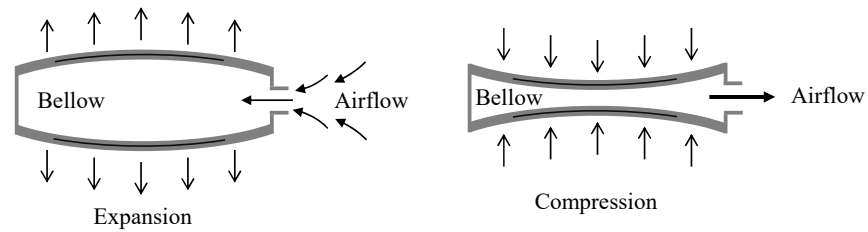

Fig. 5 The operating principle of the double bladed piezoelectric fan relied on expansion and compression cycles of the bellows to produce airflow.

\section{DEVELOPMENT OF THIN THERMAL TECHNOLOGY}

In this work, thin thermal modules comprising of flattened heat pipes and piezoelectric fans have been proposed for compact electronic devices. This section details some of the development, design and manufacturing of the flattened heat pipes and piezoelectric fans.

\subsection{Flattened heat pipes}

The heat pipes were originally circular in cross section (typically $6 \mathrm{~mm}$ outside diameter) and were consequently flattened with a hydraulic press to the prescribed thickness required. Some samples of these flattened heat pipes are shown in Fig. 6. They were made from copper with water as the working fluid.

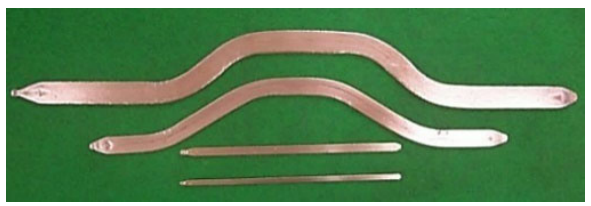

Fig. 6 Some flattened heat pipes of varying shapes and sizes.

The copper tube was first cut to length and one end was swaged. The wick was then laid in the copper tube with a carbon die. The wick consisted of $50 \mu \mathrm{m}$ copper fibers. The die was designed such that there was a small contact region between the fiber bundle and the heat pipe inner wall. The heat pipe was then sintered in an inert environment at high temperature. After this, the carbon die was removed leaving behind the fiber wick (with porosity of around $70 \%$ ). The heat pipe was charged with distilled, degassed and deionized water under vacuum conditions. Finally, it was sealed through a crimping and welding procedure.
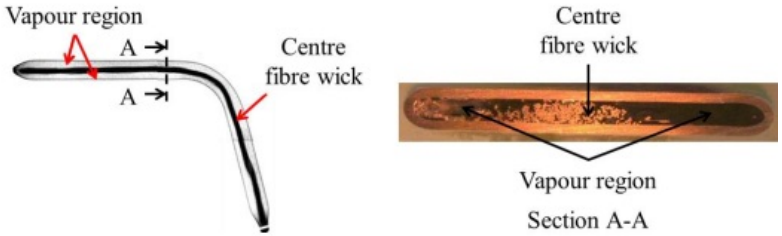

Fig. 7 X-ray image of the flattened heat pipe and cross sectional cut. Some stray fibers are seen in the cross sectional cut - these were present due to the cutting procedure only as can be confirmed by the $x$-ray image.

After this, the circular heat pipe was hydraulically pressed to the required final thickness which yielded the flattened heat pipe. Figure 7 is an x-ray and cross sectional image of the flattened heat pipe which shows the arrangement of the center fiber wick. The final thickness and width of the flattened heat pipes is listed in section 5. The effective length of the flattened heat pipes discussed in section 5 was $110 \mathrm{~mm}$ (unless otherwise stated). Further, all heat pipes from section 5 were straight unlike section 6 which included some bent heat pipes.

\subsection{Piezoelectric fans}

Two double bladed piezoelectric fans were produced. Both had the same operating principle and very similar designs however varied in their objective. The first (Fig. 8(a)) was designed to be a high flow type fan and the second (Fig. 8(b)) was designed to be a high velocity (or impingement) type fan. In both cases, two piezoelectric actuators were used. The manufacturing of each of these followed the similar route. A stainless steel plate was designed with a central hole for the piezoelectric actuator. There were two plates for each fan. The actuator was joined to each plate with an epoxy. Each plate was then joined together with silicon to form the piezoelectric fans as shown in Fig. 8. The main difference in the design of each was the shape and flow opening. The high flow type 
fan was square and had a large flow opening. The high velocity type fan was round and had a small flow opening. The high velocity fan required higher operating frequencies which led to large mechanical stresses that were better handled by round geometry without sharp corners.

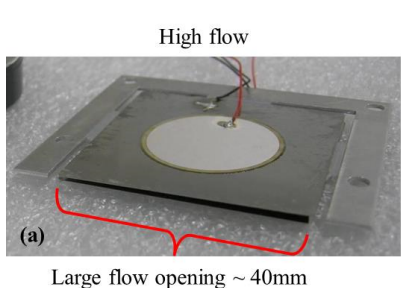

Large flow opening $\sim 40 \mathrm{~mm}$

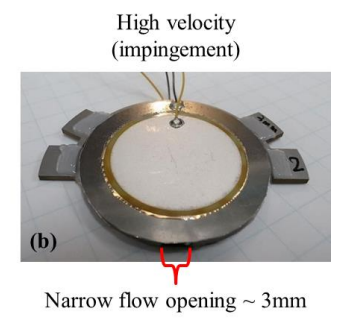

Fig. 8 The double bladed piezoelectric fans developed in this work were of two types; (a) high flow and (b) high velocity (impingement) types.

These double bladed piezoelectric fans had total thickness of $1 \mathrm{~mm}$ each. For comparison, most rotating blade DC fans that rely on bearing technology have thickness greater than $3 \mathrm{~mm}$.

\section{METHOD}

This section details the development of the experimental apparatus used to characterize performance. For the flattened heat pipes, a simple thermal performance test rig was developed. A schematic of this test rig has been shown in Fig. 9. It consisted mainly of the heat source, heat sink and flattened heat pipe. It was designed such that the temperatures at various locations on the rig could be easily measured including on the heat pipe surface and within the heat source.

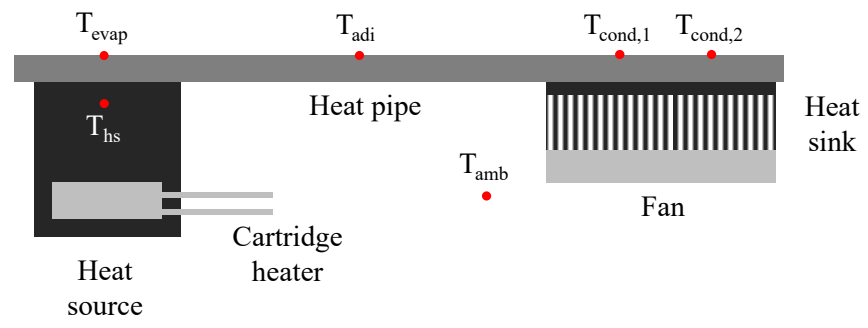

Fig. 9 The experimental setup used to characterize the performance of the flattened heat pipes with temperature measurement locations.

In this test rig, the flattened heat pipe was subject to a heat load through the heat source. This was a cartridge heater embedded within a copper block of size $20 \mathrm{~mm} \times 20 \mathrm{~mm} \times 15 \mathrm{~mm}$ (length $\times$ width $\times$ thickness). It was connected to a variable DC power supply which controlled heat input. Heat was removed from the heat pipe through the condenser section which had a heat sink and fan applied. The size of the heat sink base in contact with the flattened heat pipe was $20 \mathrm{~mm} \times 50 \mathrm{~mm}$. The fan used here was not a piezoelectric fan as this rig was only intended for measuring heat pipe performance. Thermocouples (K-type) were placed at multiple locations on the test rig. $\mathrm{T}_{\mathrm{hs}}, \mathrm{T}_{\text {evap }}, \mathrm{T}_{\mathrm{adi}}, \mathrm{T}_{\mathrm{cond}}, \mathrm{T}_{\mathrm{cond} 2}$ and $\mathrm{T}_{\mathrm{amb}}$ measured the temperature of the heat source, evaporator surface of the heat pipe, adiabatic surface of the heat pipe, condenser surface (at two locations) of the heat pipe and ambient temperature (maintained at $35 \pm 1^{\circ} \mathrm{C}$ ), respectively. Thermocouples were attached to the heat pipe with pressure sensitive adhesive tape to ensure good contact. Further, all mating surfaces had a small amount of silicon based thermal interface material applied to minimize contact resistance.

The tests performed with this setup determined the maximum heat carrying capacity of the flattened heat pipes. This was done by starting at a low heat load and waiting until steady state was achieved. Steady state was defined here as the evaporator temperature not increasing more than $0.3^{\circ} \mathrm{C}$ over a 5 minute period. Once this was achieved, the heat load was incremented. This heat load stepping was repeated until the evaporator temperature sharply and suddenly increased. The heat load at which this occurred was deemed as the maximum allowable heat load.

In section 6, various thermal modules are proposed and experimental results discussed. The experiments performed and their setups were very similar in principle and design to that of the flattened heat pipes tests. However rather than just testing a flattened heat pipe alone, these tests often involved an entire thermal module. As such these tests aimed to characterize the performance of the entire module, rather than just the heat pipe. Hence these tests measured the total thermal resistance $\left(R_{\text {tot }}\right)$ which has been defined in Eq. (1).

$$
R_{t o t}=\frac{T_{h s}-T_{a m b}}{\dot{Q}}
$$

Here $T_{h s}$ and $T_{a m b}$ are defined as in Fig. 9, and $\dot{Q}$ is the heat input to the flattened heat pipe. As mentioned above, temperature measurements were gathered with thermocouples at various locations and the heat input was measured through the variable DC power supply by monitoring the voltage and current of the cartridge heater. The rate of heat loss to the ambient was estimated based on Newton's law of cooling combined with measurements from the experimental setup. Through this process it was estimated that the rate of heat loss from the heat source to the ambient was below $1 \%$. By defining the total thermal resistance as in Eq. (1), the effect of all components of the thermal module can be included. Besides, this value is of most interest to thermal designers. Since the experimental setup for all the thermal modules in this work is very similar to the flattened heat pipe setup as described above, these are not individually described for brevity. The reader is referred to Fig. 9 for a general description of these setups.

Lastly, the piezoelectric fans were tested with a dedicated airflow measurement setup. Within this setup, a flow measuring device with flow rate and pressure uncertainty of $\pm 41 / \mathrm{min}$ and $\pm 2 \mathrm{~Pa}$, respectively, (Tsukubarikaseiki, model F43-B) was used to measure the piezoelectric fan characteristics. By performing tests using this setup, the pressureflow rate curve could be generated for the high flow piezoelectric fan and velocity profiles could also be measured for the high velocity piezoelectric fan. The AC input signal (frequency and root mean square (RMS) voltage) of these fans, which dictated the frequency and amplitude of actuator vibration, could be electronically controlled.

Uncertainty analysis has been performed according to the Taylor series method proposed in Coleman and Steele (2018). The measurement uncertainty in the voltage and current of the DC power supply was $0.1 \mathrm{~V}$ and $0.01 \mathrm{~A}$, respectively, and in the thermocouples was $0.5^{\circ} \mathrm{C}$. The resulting uncertainty in the heat input was less than $4 \%$ for all loads tested in this work. Propagation of this led to uncertainty of less than $7 \%$ for the reported total thermal resistance of the modules described in this work.

\section{EXPERIMENTAL RESULTS}

The experimental results and performance of the flattened heat pipes and piezoelectric fans will now be discussed.

\subsection{Flattened heat pipes}

The flattened heat pipes were first tested with the experimental setup such that the maximum allowable heat load could be determined. The results of this are shown in Fig. 10. This was done for heat pipes with flattened thickness in the range of $0.8-2.0 \mathrm{~mm}$. The final width has also been included in Fig. 10.

The maximum heat carrying capacity was found to be a function of the flattened thickness, with thinner flattened heat pipes having smaller heat carrying capacity than thicker ones. The initial un-pressed heat pipe could carry a heat load of around $60 \mathrm{~W}$, however when pressed to a final flattened thickness of $0.8 \mathrm{~mm}$, the heat carrying capacity reduced to around $7 \mathrm{~W}$. 


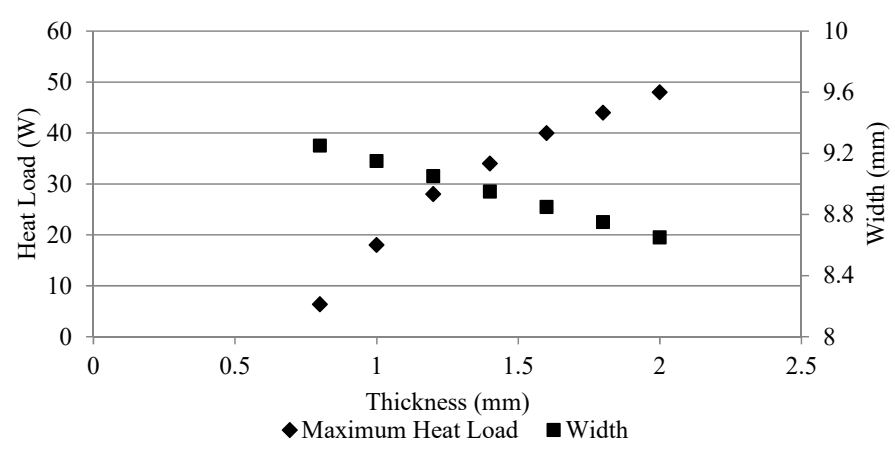

Fig. 10 The maximum heat load as a function of flattened thickness for heat pipes with original diameter of $6 \mathrm{~mm}$. This graph also shows the final width as function of thickness.

This reduction in heat transport capabilities was likely due to capillary limitations within the heat pipe being reached. Once the capillary limit was reached and dry-out occurred, poor performance would typically result. The capillary limit can be described with Eq. (2).

$$
\Delta P_{c}=\Delta P_{l}+\Delta P_{v}+\Delta P_{g}
$$

Here $\Delta P_{c}$ is the capillary pressure generated by the wick, $\Delta P_{l}$ is the liquid pressure loss of the working fluid in the wick, $\Delta P_{v}$ is the vapor pressure loss of the working fluid in the vapor region and $\Delta P_{g}$ represents any gravitational pressure losses (these are neglected here since the heat pipes were tested in horizontal arrangement). Using some standard relations available for the liquid and vapor pressure losses reveals the importance of geometric properties on this limit. This has been shown in Eq. (3) which calculates the maximum heat carrying capacity $\left(\dot{Q}_{\max }\right)$ according to the capillary limit of a heat pipe (Faghri, 2016). Here it was assumed that fluid flow was laminar, incompressible and that the wet point was at the end of the condenser section.

$$
\dot{Q}_{\text {max }}=\frac{2 \sigma}{r_{e f f} \cdot l_{e f f}} \frac{1}{F_{l}+F_{v}}
$$

Where the liquid $\left(F_{l}\right)$ and vapor $\left(F_{v}\right)$ frictional pressure loss coefficients are defined in Eqs. (4) and (5) (Faghri, 2016):

$$
\begin{aligned}
& F_{l}=\frac{\mu_{l}}{\rho_{l} h_{f g} A_{w} K} \\
& F_{v}=\frac{\left(f_{v} R e_{v, h}\right) \mu_{v}}{2 r_{v . h}^{2} A_{v} \rho_{v} h_{f a}}
\end{aligned}
$$

Here $\sigma, \mu, \rho$ are properties of the working fluid (surface tension, dynamic viscosity and density, respectively) in the liquid $(l)$ and vapor (v) states and $h_{f g}$ is the latent heat of evaporation of the working fluid. $r_{e f f}$ and $K$ are wick properties (effective pore radius and permeability). $A_{w}, A_{v}, r_{v, h}$ and $l_{e f f}$ are geometric properties of the heat pipe (wick cross sectional area, vapor region cross sectional area, vapor region hydraulic radius and effective heat pipe length, respectively). $f_{v}$ and $R e_{v, h}$ are friction factor and Reynolds number relating to the vapor flow.

The heat carrying capacity is a function of many factors as seen in these equations. From a geometric perspective, it is a function of the flow areas of the liquid and vapor regions and the hydraulic radius of the vapor region. Any reductions in these values will increase the friction pressure loss factors $\left(F_{l}\right.$ and $\left.F_{v}\right)$, thereby reducing the heat carrying capacity.

Flattening of the heat pipes can be shown to be very detrimental to the performance since the flow areas and hydraulic radius are greatly reduced through this procedure. This will now be further explored. The original circular heat pipe had total inside area of approximately $28.27 \mathrm{~mm}^{2}$. This total area was shared between the liquid and vapor regions of the heat pipe; the wick region would contain the liquid flow and the remaining area (vapor region) would contain the vapor flow. As the heat pipe was flattened, the material which formed the heat pipe wall was redistributed to form a new cross section. Given that the total volume of material (not total inside area) was conserved through this flattening procedure, the perimeter of each formed cross section would remain approximately constant. This has been shown schematically with the aid of Fig. 11.

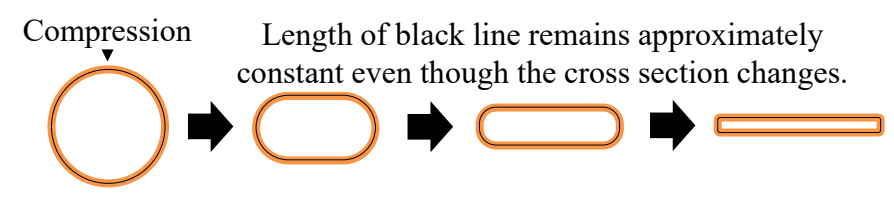

Fig. 11 The flattening of the circular heat pipe would tend to make a rounded rectangle shape as the material was redistributed from the original shape.

It can also be observed from Fig. 11 that the cross section approximates that of a rectangle as the heat pipe becomes more flattened. Thus the cross sectional area and perimeter could be estimated from rectangular geometry and initial conditions as the heat pipe was flattened. Some simple geometric analysis shows that the area of a rectangle with fixed perimeter decreases with an increase in the rectangle aspect ratio (width-to-thickness ratio). Hence the more flattened the heat pipe becomes, the more the area reduces. The variation in internal flow area of the heat pipe (liquid and vapor flow areas combined) with the flattened thickness has been shown in Fig. 12 (maximum heat load has also been included). In this, the flattened heat pipe cross section was assumed rectangular; the round edge curvature was neglected for simplicity as discussed above. This was deemed a reasonable assumption for the small thickness of heat pipes.

The trends observed in Fig. 12 suggest there is a correlation between the internal flow area and maximum heat load of the flattened heat pipe. It also shows the flattening procedure will lead to drastic reductions in flow area purely by altering the heat pipe cross sectional shape. Flattening the heat pipe to $0.8 \mathrm{~mm}$ reduced the flow area to less than one quarter the original value. This redistribution of metal from the heat pipe wall into a new cross sectional shape gives sub-optimal conditions that yield less area for the same perimeter (or amount of material).

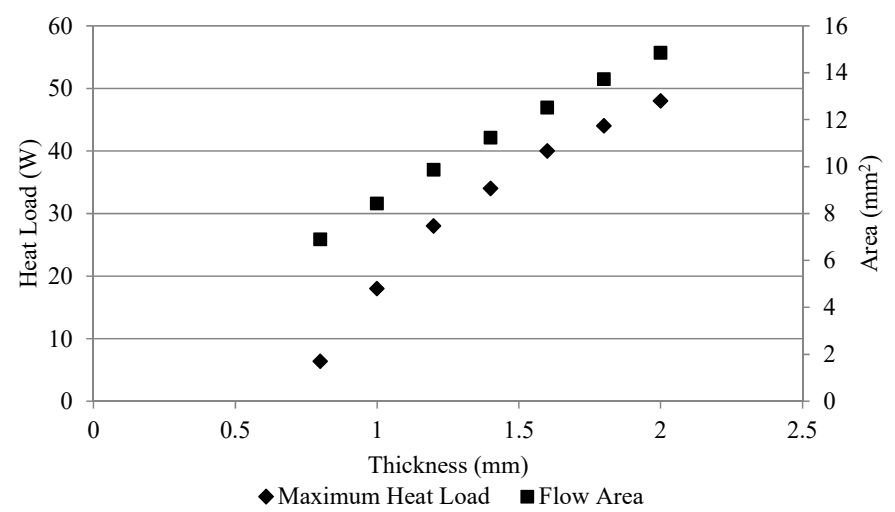

Fig. 12 The effect of flattened thickness on the internal flow area of the heat pipe based on assumptions of rectangular cross section.

This flattening procedure not only leads to reductions in flow area as described above, but consequently also reduces the hydraulic radius of the vapor region (since this itself is a function of the cross sectional area). Further, this term is raised to power two in Eq. (5) so it dominates the final value. All the aspects described above lead to an increase in the friction pressure loss factors $\left(F_{1}\right.$ and $\left.F_{v}\right)$ and thus total fluid pressure 
loss. This would reduce the maximum heat capacity $\left(\dot{\mathrm{Q}}_{\max }\right)$ according to Eq. (3). To explore this further, an estimation of vapor pressure losses was carried out according to the procedure in Faghri (2016), as outlined by Eq. (6).

$$
\Delta P_{v}=F_{v} \dot{Q} l_{e f f}
$$

Here $\dot{Q}$ can represent any heat load. It was further assumed that the vapor region could be modelled as a rectangular groove and that vapor properties were constant. These estimations have been shown in Fig. 13 as a function of heat load at various flattened heat pipe thicknesses. In this, the estimation of vapor pressure losses for the original heat pipe (circular cross section) has also been calculated.

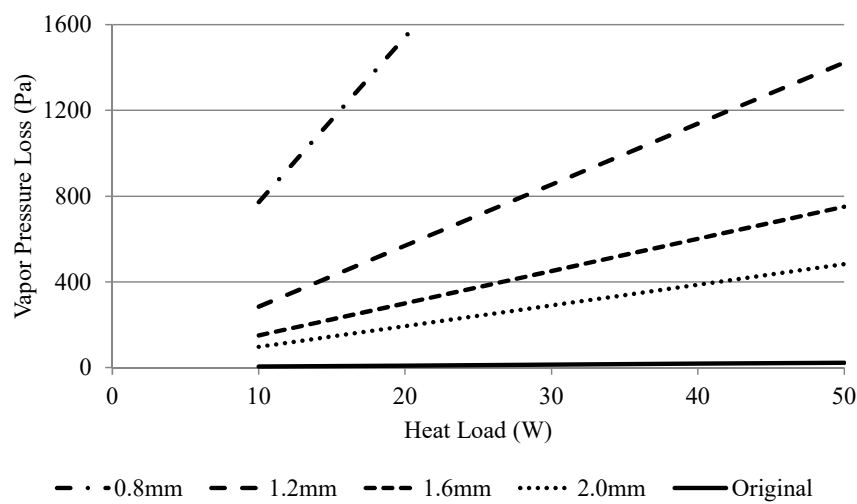

Fig. 13 The estimation of vapor pressure losses for flattened heat pipes at various thicknesses and the original circular heat pipe as a function of heat load.

Figure 13 clearly shows the practical implications of the flattening procedure. Reducing the flattened heat pipe thickness severely increases vapor pressure losses. At a heat load of $10 \mathrm{~W}$, losses for the $0.8 \mathrm{~mm}$ case were estimated to be about 170 times larger than the original heat pipe. This is a result of increasing the vapor friction coefficient $\left(F_{v}\right)$ as previously described. The extreme sensitivity of vapor pressure losses to small thicknesses has also been identified through other numerical modelling techniques as a critical parameter for flattened heat pipe development (Koito, 2019).

Due to the distribution of the initial wick on the circular heat pipe, it was expected that the flow area of the vapor phase would be more greatly influenced by flattening than the liquid phase. This is because the wick cross section was only modestly altered (if at all) by the flattening procedure, whereas the vapor flow region (non-wick area) was drastically altered. Hence it was expected that the vapor region cross sectional area and hydraulic radius would have been most strongly affected by this flattening procedure, thereby resulting in the large vapor pressure losses as estimated in Fig. 13.

Since the vapor region was greatly reduced through the flattening procedure, it could also be reasoned that the entrainment limit would be relevant. Entrainment occurs when the vapor velocity becomes so large that the shear force generated at the liquid-vapor interface causes liquid to be drawn into the vapor flow. This prevents the liquid from returning to the evaporator and leads to poor thermal performance. A theory based on the Weber number (Faghri, 2016) has been used to describe the entrainment limit for heat pipes as shown by Eq. (7).

$$
\dot{Q}_{\text {max }}=A_{v} h_{f g}\left(\frac{\sigma \rho_{v}}{2 r_{h . w}}\right)^{1 / 2}
$$

All these terms are the same as their previous definitions, except for $\mathrm{r}_{\mathrm{h}, \mathrm{w}}$ which is the hydraulic radius of the wick structure. Here it can be seen that there are two geometric terms; vapor region cross sectional area and wick hydraulic radius. The flattening procedure would reduce the vapor region cross section as described previously, thereby reducing the entrainment limit. Conversely, the flattening procedure could slightly compact the fiber wick and thus reduce the wick hydraulic radius which would be beneficial. This effect would likely be minimal compared to changes in the vapor cross sectional area, in part due to the square root dependence in Eq. (7). It is also generally expected that the entrainment limit would be less critical than the capillary limit in this scenario due to the above discussions.

The described effects are necessary consequences of flattening heat pipes. In fact, the circle is the geometric shape which maximizes cross sectional area for a given perimeter. Hence circular shapes are very beneficial for heat pipes and other fluid transport systems. Changing the cross section to any polygon will reduce the area for a given perimeter. The area is further reduced as the rectangle becomes more flattened. Nevertheless, the use of circular heat pipes with very small diameters may not be practical even though they maximize the flow area; thermal contact between the circular heat pipe and heat source could introduce new difficulties (Singh et al., 2007). The surface of the flattened heat pipe is ideal for thermal contact onto a heat generating component such as ICs which often have high degrees of surface flatness.

The four sided polygon that maximizes area is a square. This cross section is also not always practical since it requires that all side lengths be equal, thus small thicknesses would result in small widths. It is further complicated when the sides needs to be on a millimeter (and submillimeter) scale which imposes further manufacturing issues. Hence the rectangular cross section is simpler and more cost effective to manufacture than the square cross section.

Compact electronic devices such as mobiles phones require heat dissipation in the range of $10 \mathrm{~W}$, hence a flattened heat pipe with submillimeter thickness should be appropriate. Devices such as tablets require heat dissipation as high as $20 \mathrm{~W}$. Various laptops may draw larger heat loads, but could also use thicker modules since there is more space available in these devices.

In cases where larger heat loads need to be carried without increasing thickness, it was proposed to use larger initial diameter copper tube flattened to the same final thicknesses. In this case, the same design and manufacturing process was followed. Pressing the larger initial diameter tube to the same final thicknesses meant that the final width of the flattened heat pipe would vary. Using flattened heat pipes of constant thickness and varying width, the same maximum heat load tests have been performed. These results have been shown in Fig. 14 for flattened heat pipes with thickness of $1 \mathrm{~mm}$ and $2 \mathrm{~mm}$. In this case, the effective length of the heat pipe was reduced to $80 \mathrm{~mm}$.

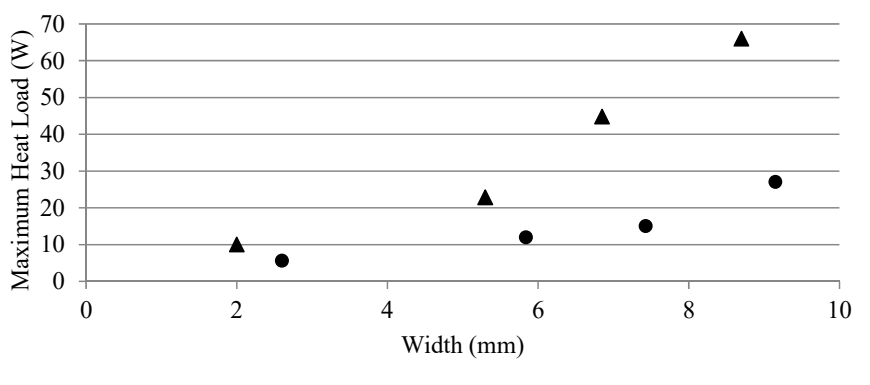

- Flattened thickness $=1 \mathrm{~mm} \quad \boldsymbol{\Delta}$ Flattened thickness $=2 \mathrm{~mm}$

Fig. 14 The maximum heat load as a function of width for flattened heat pipes with thickness of $1 \mathrm{~mm}$ and $2 \mathrm{~mm}$.

In Fig. 14 it can be seen that maximum heat load was a function of heat pipe width. For the $1 \mathrm{~mm}$ thick and flattened heat pipe, the maximum heat load varied between $5.6-27 \mathrm{~W}$. For the $2 \mathrm{~mm}$ thick flattened heat pipe, the maximum heat load varied between $10-66 \mathrm{~W}$. As the heat pipe width increased, the maximum heat load also increased due to larger heat pipe flow areas. The increase in flow area would reduce the liquid and vapor 
phase pressure losses and hence extend the capillary limit. The heat pipe thickness also influenced the maximum heat load in similar ways, as discussed earlier.

\subsection{Piezoelectric fan}

Both the high flow and high velocity double blade piezoelectric fans were tested in the airflow measurement rig to assess their performance. For the high flow fan, the pressure-flow rate curve was generated, as in Fig.15. Since the piezoelectric actuator responded differently based on the input AC signal, this was done for two different inputs that were found to represent the upper and lower bounds for device performance. These results form a performance enveloped which has been shown in Fig. 15 for the $40 \mathrm{~mm} \times 40 \mathrm{~mm} \times 1 \mathrm{~mm}$ piezo fan.

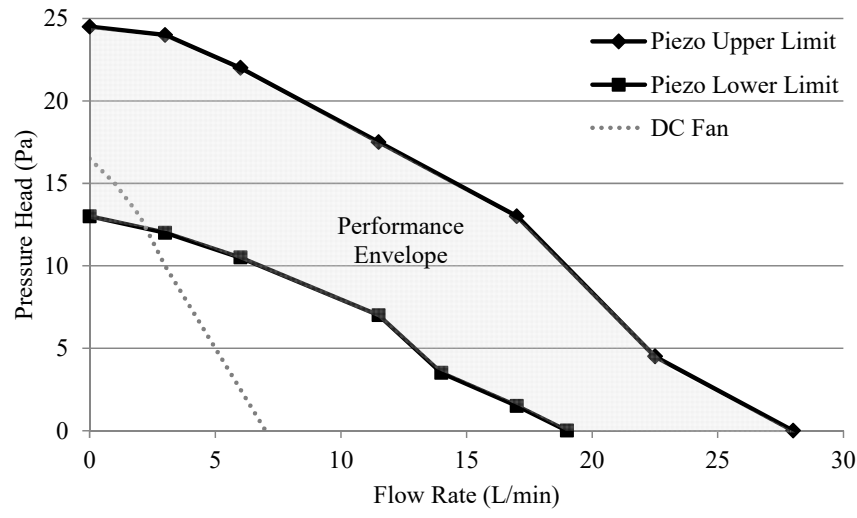

Fig. 15 The performance envelope of the high flow double bladed piezoelectric fan. The performance curve of a similarly sized DC fan with $3 \mathrm{~mm}$ thickness has also been included here.

The input $\mathrm{AC}$ voltage and frequency which represented the upper limit was $50 \mathrm{Vrms}$ and $182 \mathrm{~Hz}$, respectively, and $35.5 \mathrm{Vrms}$ and $175 \mathrm{~Hz}$, respectively, for the lower limit. The maximum volume flow rate produced for the upper and lower limits was $28 \mathrm{~L} / \mathrm{min}$ and $19 \mathrm{~L} / \mathrm{min}$, respectively. The input signal thus had a large influence on the performance of the piezoelectric fan and must be carefully selected and optimized for each particular arrangement.

As seen in Fig. 15, the low flow condition for the piezoelectric fan had performance which is close to but inferior to similar sized DC fan. The high flow condition had performance which significantly exceeded the DC fan. In terms of power consumption, the low flow condition required only $283 \mathrm{~mW}$ of electrical power, compared to about $360 \mathrm{~mW}$ for the DC fan. The high flow condition also required electrical power consumption of less than $350 \mathrm{~mW}$.

The input signal for the piezoelectric fan is clearly different to typical DC fans which normally require $12 \mathrm{~V}$ DC power input. A signal processing unit was required to achieve this input signal for the piezoelectric fan. This also allowed for multiple input signals which, as described above, could lead to different fan performance depending on the needs of the system. When in a thermally challenging environment, the input signal could switch to produce the highest flow, and when in an idle state the input signal could switch to produce lower flow. In essence, piezo fan can act like a DC fan with PWM control.

The high velocity piezoelectric fan was tested to measure the jet of air produced from the flow opening during operation. Rather than obtaining the fan performance (pressure-flow rate) curve, the flow velocity profile, measured normal to the flow opening, was obtained. The air flow velocity is more important for impingement type cooling than the volume of air flow produced. These results have been shown in Fig. 16.

It is seen from Fig. 16 that air velocities as high as $7.5 \mathrm{~m} / \mathrm{s}$ were obtained within $10 \mathrm{~mm}$ from the flow opening. The velocity decreased substantially throughout the first $20 \mathrm{~mm}$, due to spreading of the air jet from the narrow opening. The profile tapered off through the next $60 \mathrm{~mm}$. The velocity at $80 \mathrm{~mm}$ from the opening was $1.4 \mathrm{~m} / \mathrm{s}$. This high velocity fan operated with a different input signal to the high flow fan; 40Vrms and $540 \mathrm{~Hz}$ were required to obtain high velocity jets. Still this signal can be obtained with relatively simple electronic controls.

These discussions have shown the performance of piezoelectric fans in high flow and high velocity modes. The high flow fan has a performance envelope that must be carefully considered when selecting the input signal. Large improvements over typical DC fans can be realized by the correct input signal. The potential of piezoelectric fans for impingement cooling has also been explored. The high velocity jet could be useful for direct cooling of hotspots in electronic devices. The size of these devices is not limited to the ones described here. Thickness reductions into the sub-millimeter range are possible as are increases to the device length and width.

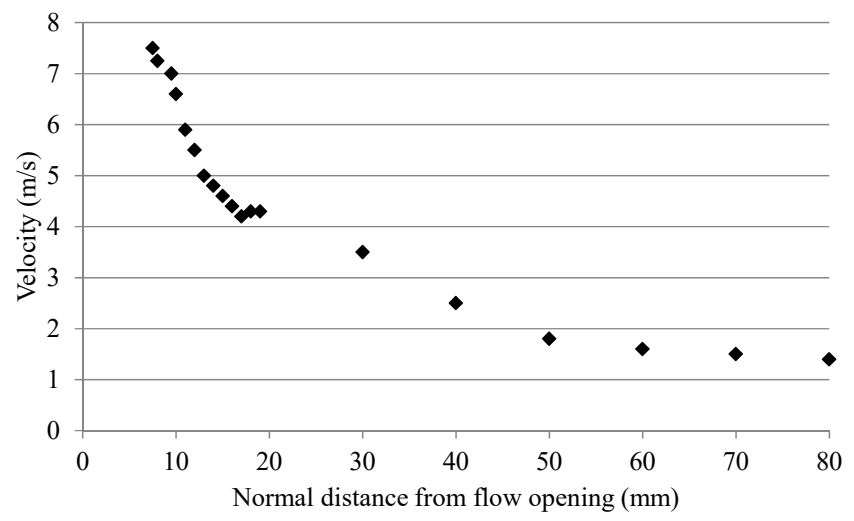

Fig. 16 The velocity profile measured normal to the flow opening of the high velocity (impingement) type piezoelectric fan.

\section{THIN THERMAL MODULES}

In this section, some thin thermal modules which are based on the previously introduced technology are presented. These modules showcase some of the possible configurations which could be utilized for thermal management of various compact electronic devices. In these discussions, some experimental results are provided. These setups are not explicitly discussed for each thermal module. As mentioned previously, they were very similar in principle and design to that of the flattened heat pipe test rig.

\subsection{Flattened heat pipe heat spreader}

Initially, a simple heat spreader based on flattened heat pipes has been introduced as shown in Fig. 17. This heat spreader relies on the flattened heat pipe transferring heat from the heat source to the thin metal plate. The metal plate also acts as a fin which dissipates heat to the ambient. The heat pipe can be soldered to the thin metal plate to ensure good thermal contact. Such a system could be used for very thin, low powered electronic devices that cannot typically use forced convection such as mobile phones.

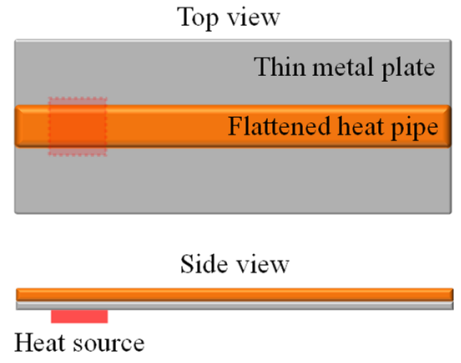

Fig. 17 The simple heat spreader based on flattened heat pipe technology. 
The performance of a solid metal heat spreader is limited by the thermal conductivity of the metal; around $400 \mathrm{~W} / \mathrm{mK}$ for copper and $210 \mathrm{~W} / \mathrm{mK}$ for aluminum. The heat transfer ability of the heat pipe ensures heat is effectively transferred along the spreader. A comparative study was performed between the heat pipe heat spreader and solid metal heat spreader. The heat pipe module consisted of a $1 \mathrm{~mm}$ thick aluminum plate $(20 \mathrm{~mm} \times 100 \mathrm{~mm})$ soldered to a $0.6 \mathrm{~mm}$ thick flattened heat pipe. The solid metal module was copper with equivalent dimensions. The test configuration was similar to Fig. 17 with natural convection. The heat pipe module could reduce the heat source temperature by about $10^{\circ} \mathrm{C}$ for a $3 \mathrm{~W}$ heat load from a $10 \mathrm{~mm} \times 10 \mathrm{~mm}$ heat source. A further study was performed using a heat spreader which combined aluminum and graphite (high lateral thermal conductivity) into one module. Both heat spreaders had size of $110 \mathrm{~mm} \times 65 \mathrm{~mm}$ with aluminum thickness of $0.3 \mathrm{~mm}$. Thermal imaging of the top surface of these is shown in Fig. 18 when exposed to multiple heat sources on the module underside.

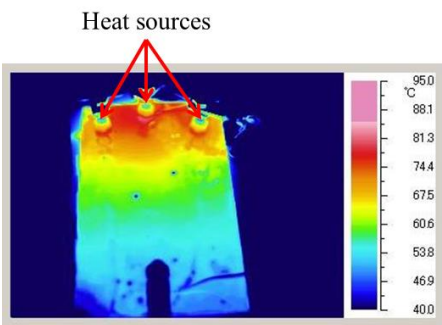

Graphite heat spreader

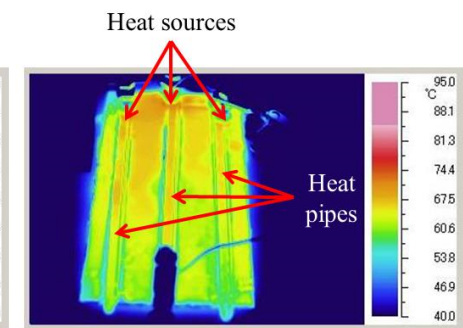

Heat pipe heat spreader
Fig. 18 Thermal imaging showing the different temperature distributions between the graphite and the flattened heat pipe heat spreaders exposed to multiple heat sources.

As seen in Fig. 18, the heat pipe heat spreader could maintain the temperature of the heat sources consistently lower than the graphite heat spreader. Further, the temperature uniformity is superior for the heat pipe module. This is an advantageous for mobile phones and tablets where user comfort dictates that hotspots must be avoided.

\subsection{Direct cooling piezoelectric fan}

It has been previously discussed that the piezoelectric fan can be designed and operated for either high flow or high velocity conditions. The high velocity design can be used for direct cooling of heat generating elements like in impingement cooling methods. This direct cooling mode has been shown schematically in Fig. 19.

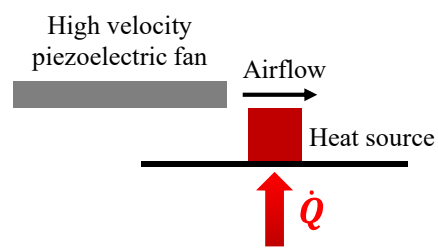

Fig. 19 Direct cooling of a heat source with a high velocity piezoelectric fan. The piezoelectric fan could also be located directly above the heat source, depending on available space.

Such system has also been explored in this work. A high velocity piezoelectric fan ( $1 \mathrm{~mm}$ thickness) was oriented parallel to a $5 \mathrm{~mm} \times 5 \mathrm{~mm}$ heat source like shown in Fig. 19. The temperature of the heat source was monitored with both natural convection and piezoelectric cooling methods. The results of this test are shown in Fig. 20.

These results show the direct cooling capabilities of the high velocity piezoelectric fan. The heat source temperature could be kept to less than $90^{\circ} \mathrm{C}$ with a heat load of $5 \mathrm{~W}$. For the natural convection case, a heat load of $2 \mathrm{~W}$ led to nearly the same heat source temperature. Thus the operating range was extended nearly 2.5 times with the piezoelectric fan.
Such modules would be valuable in low power electronics where space constraints are very strict. Here DC fans may be too thick to use, and external heat sinks sizes must be minimized.

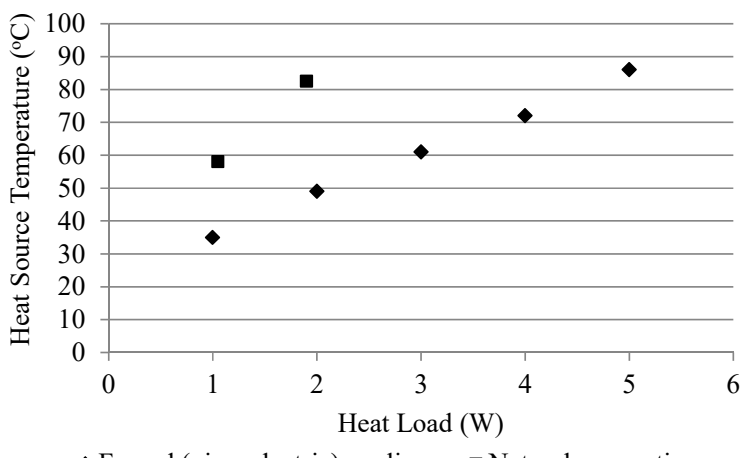

- Forced (piezoelectric) cooling $\quad$ Natural convection

Fig. 20 The comparison between natural convection cooling of a $5 \mathrm{~mm}$ $\times 5 \mathrm{~mm}$ heat source against forced convection with the high velocity piezoelectric fan.

\subsection{Flattened heat pipe module with DC fans}

A DC fan could also be combined with flattened heat pipes to form thermal modules with a possible configuration shown in Fig. 21. In this a $300 \mathrm{~mm}$ long, $1.3 \mathrm{~mm}$ thick flattened heat pipe was subject to a centrally located heat source. Finned heat sinks were attached to both ends of the heat pipe to dissipate to the ambient. The maximum thickness of this module was $5 \mathrm{~mm}$.

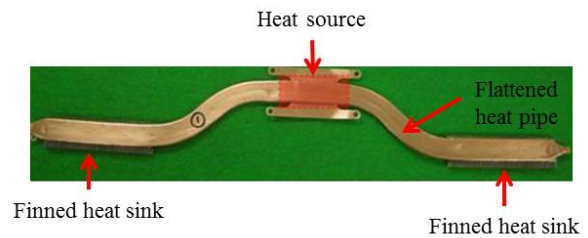

Fig. 21 Thermal module based on flattened heat pipes with DC fan cooling (fans not shown).

The thermal performance of the above module has been tested with flattened heat pipes of two different widths; $9 \mathrm{~mm}$ and $12 \mathrm{~mm}$. The total thermal resistance has been shown in Fig. 22 for both modules.

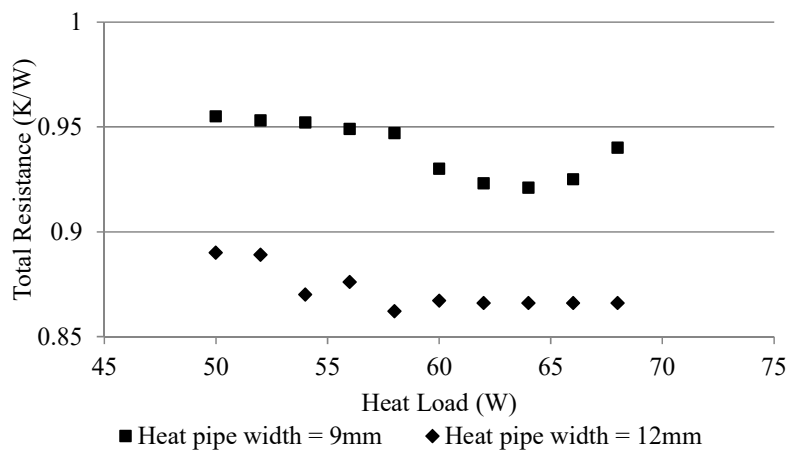

Fig. 22 The total thermal resistance of various flattened heat pipe based modules with DC fans.

The performance of these modules, both with the same thickness, was a function of heat pipe width and heat load. As expected, the wider heat pipe module had lower total resistance. The total thermal resistance for the $9 \mathrm{~mm}$ and $12 \mathrm{~mm}$ width modules was $0.92 \mathrm{~K} / \mathrm{W}$ and $0.87 \mathrm{~K} / \mathrm{W}$, respectively. The wider module could also carry a larger heat load $(68 \mathrm{~W})$ than the smaller module $(64 \mathrm{~W})$ without performance degrading. 
Similar thermal modules based on flattened heat pipes with DC fans have been proposed in Fig. 23. Unlike Fig. 21, these modules have a single heat source located at one end of the flattened heat pipe. The module on the left used a flattened heat pipe with thickness of $1 \mathrm{~mm}$ and the module on the right used a flattened heat pipe with thickness of $0.8 \mathrm{~mm}$. Both had total thickness of about $4 \mathrm{~mm}$.

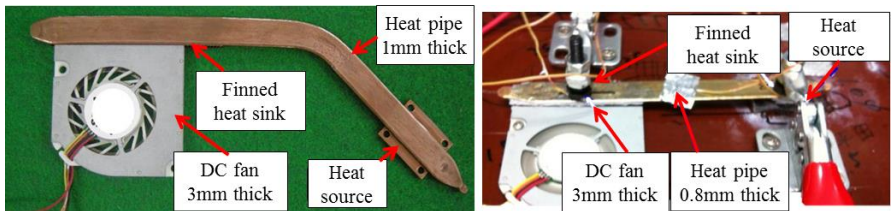

Fig. 23 Some further flattened heat pipe modules with DC fans. Both modules had total thickness of about $4 \mathrm{~mm}$.

The performance of these thermal modules has been shown in Fig. 24. These results show that the total thermal resistance of the $0.8 \mathrm{~mm}$ thick heat pipe module was in the range of $1.8-2.2 \mathrm{~K} / \mathrm{W}$ and the $1 \mathrm{~mm}$ thick heat pipe module in the range $0.5-0.6 \mathrm{~K} / \mathrm{W}$. The thinner module had $7 \mathrm{~W}$ heat carrying capacity to $18 \mathrm{~W}$ for the thicker module before performance degraded.

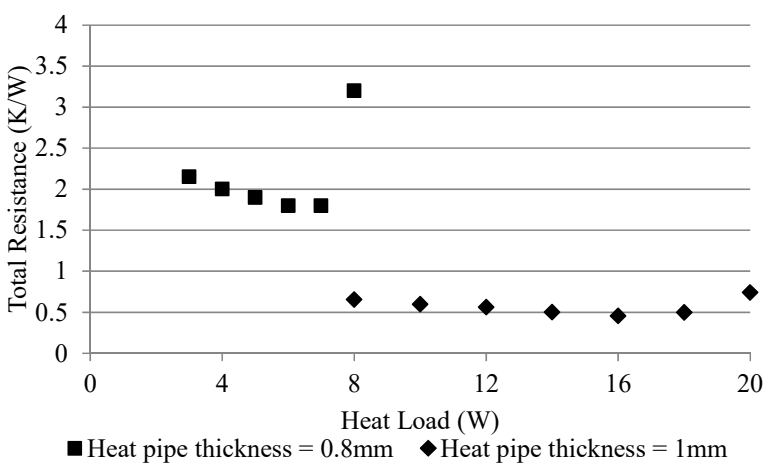

Fig. 24 The thermal performance of various flattened heat pipe based thermal modules with differing heat pipe thickness and DC fans.

Note that direct comparisons of these modules are difficult to make due to differences between the modules including thickness and width of the flattened heat pipe, finned heat sink and fan combination, and effective length of the flattened heat pipe. This work simply explored some combinations for this type of thermal module and provided some basic performance data.

These thermal modules with flattened heat pipes and DC fans have shown to be capable of handling heat loads in the range of $3-68 \mathrm{~W}$ with total thermal resistance between $0.5-2.2 \mathrm{~K} / \mathrm{W}$. These types of thermal modules could be suitable for the thermal management of electronic devices such as laptops with more space to accommodate thicker fans, which can perform active cooling.

\subsection{Flattened heat pipe module with piezoelectric fans}

An alternative to the thermal modules discussed in the previous section are proposed here, with DC fans replaced by piezoelectric fans. The combination of flattened heat pipes and piezoelectric fans can produce thin thermal modules which are reliable, high performance, low noise and have low power consumption. A visual comparison has been included in Fig. 25.

The piezoelectric module shown in Fig. 25 consisted of a $1 \mathrm{~mm}$ thick flattened heat pipe, $2 \mathrm{~mm}$ thick piezoelectric fan (operating in high flow mode) and a $3 \mathrm{~mm}$ thick finned heat sink. The maximum thickness of the module was less than $4 \mathrm{~mm}$. This module was able to dissipate heat load of more than $10 \mathrm{~W}$ from a $10 \mathrm{~mm} \times 10 \mathrm{~mm}$ heat source while keeping the temperature below $90^{\circ} \mathrm{C}$. Further testing was performed on a similar thermal module with maximum thickness of $6 \mathrm{~mm}$ and heat source size of $10 \mathrm{~mm} \times 10 \mathrm{~mm}$. It is shown in Fig. 26 .
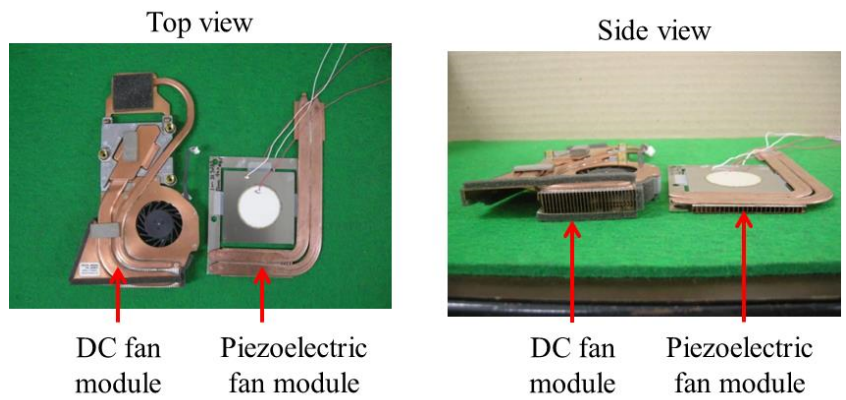

Fig. 25 A visual comparison of a thermal module consisting of traditional DC fans compared to piezoelectric fans with flattened heat pipes, as proposed in this work.

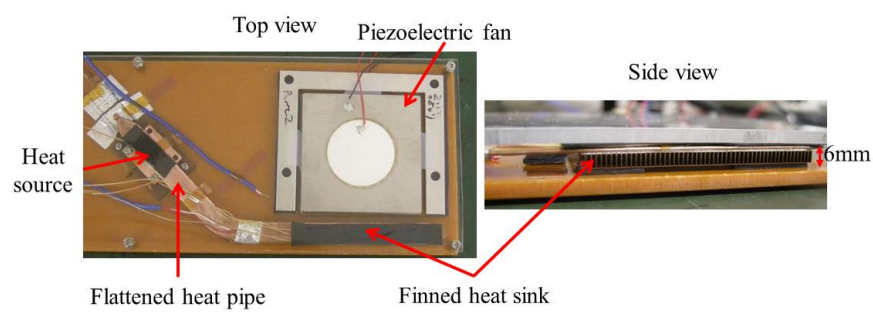

Fig. 26 A thin thermal module consisting of a flattened heat pipe and piezoelectric fan with maximum thickness of $6 \mathrm{~mm}$.

The thermal performance of this module was tested and the total thermal resistance is shown in Fig. 27 (module thickness $=6 \mathrm{~mm}$ ). The minimum thermal resistance measured with this module was $5.5 \mathrm{~K} / \mathrm{W}$ at a heat load of $10 \mathrm{~W}$. At this load, the heat source temperature was maintained below $90^{\circ} \mathrm{C}$.

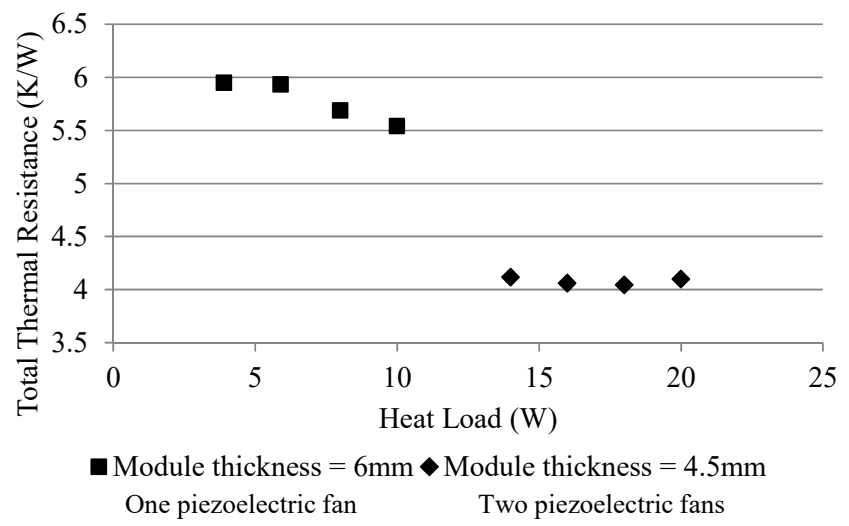

Fig. 27 Total thermal resistance for thermal modules with flattened heat pipes and piezoelectric fans. The $6 \mathrm{~mm}$ thick module (Fig. 26) had single fan and $4.5 \mathrm{~mm}$ thick module (Fig. 28 ) had two fans.

A thinner module is proposed in Fig. 28. The maximum thickness here was below $4.5 \mathrm{~mm}$ by using two piezoelectric fans with $1.5 \mathrm{~mm}$ thickness and a single flattened heat pipe with $1.5 \mathrm{~mm}$ thickness. The heat source was located in the center of the flattened heat pipe which had length of $175 \mathrm{~mm}$. Both ends of the flattened heat pipe had attached finned heat sinks with separate piezoelectric fan dedicated to each.

Similar tests were performed and the total thermal resistance has also been shown in Fig. 27 (module thickness $=4.5 \mathrm{~mm}$ ). Constant thermal resistance of $4.1 \mathrm{~K} / \mathrm{W}$ was seen in the heat load range of $14-20 \mathrm{~W}$. Beyond these loads, the thermal performance of the module degraded. The maximum capacity of the flattened heat pipe and piezoelectric fan thermal modules was about $20 \mathrm{~W}$ in the shown configurations. 


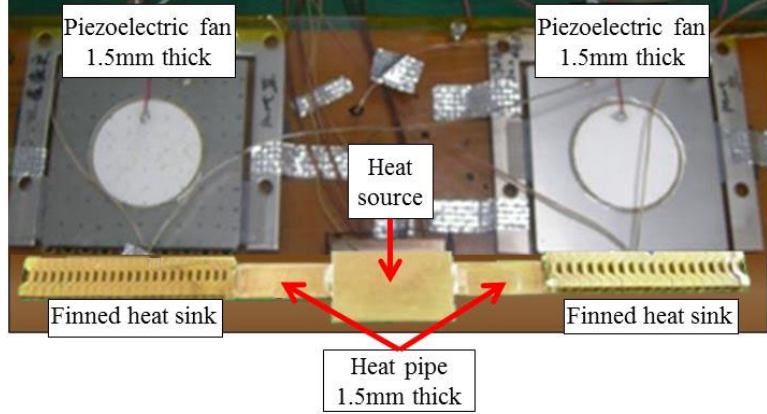

Fig. 28 Thin thermal module (4.5mm thick) consisting of a flattened heat pipe and multiple piezoelectric fans.

This is an attractive solution for portable electronic devices such as laptops which can benefit from reduced thickness, low noise and low power consumption. With the increasing demands and miniaturization of electronics, combination of thin flattened heat pipes and piezo fans present an interesting opportunity for future thermal management systems however they need to be further explored and developed.

\section{CONCLUSIONS}

This paper discussed various performance aspects of flattened heat pipes and piezoelectric fans. The maximum heat carrying capacity of the flattened heat pipe strongly depended on the flow area, which itself depended on the final thickness of the flattened heat pipe. Reducing thickness from $2.0 \mathrm{~mm}$ to $0.8 \mathrm{~mm}$ reduced the maximum heat load from $48 \mathrm{~W}$ to $7 \mathrm{~W}$. It was expected that this was primarily due to the capillary limit, which was found to be strongly affected by the flattening of heat pipe. Extension of the heat load range could be achieved with flattened heat pipes of larger width. The piezoelectric fan could be operated in both high flow and high velocity modes depending on the requirements. The high flow mode performance was a function of the input signal. The high velocity mode could produce air velocity up to $7.5 \mathrm{~m} / \mathrm{s}$. The implementation of these devices into thin thermal modules was also explored and various embodiments were proposed for compact electronic devices. Although promising performance was observed, further research and development on these components is required.

\section{NOMENCLATURE}

\section{A area $\left(\mathrm{m}^{2}\right)$}

$f_{v} \quad$ friction factor relating to vapor flow

$F \quad$ friction coefficient $\left(\mathrm{s} / \mathrm{m}^{4}\right)$

$h_{f g} \quad$ latent heat of evaporation $(\mathrm{J} / \mathrm{kg})$

$K \quad$ permeability $\left(\mathrm{m}^{2}\right)$

$l_{\text {eff }} \quad$ effective heat pipe length (m)

$\Delta P \quad$ pressure loss $(\mathrm{Pa})$

$\dot{Q} \quad$ heat transferred (W)

$r_{\text {eff }} \quad$ effective pore radius (m)

$\mathrm{r}_{\mathrm{h}, \mathrm{w}} \quad$ hydraulic radius of wick structure $(\mathrm{m})$

$\mathrm{r}_{\mathrm{v}, \mathrm{h}} \quad$ hydraulic radius of vapor region $(\mathrm{m})$

$\mathrm{R}_{\text {tot }} \quad$ total thermal resistance $(\mathrm{K} / \mathrm{W})$

$R e_{v, h} \quad$ Reynolds number for vapour flow

$\mathrm{T}$ temperature $\left({ }^{\circ} \mathrm{C}\right)$

Greek Symbols

$\begin{array}{ll}\rho & \text { density }\left(\mathrm{kg} / \mathrm{m}^{3}\right) \\ \mu & \text { dynamic viscosity }(\mathrm{kg} / \mathrm{ms}) \\ \sigma & \text { surface tension }(\mathrm{N} / \mathrm{m})\end{array}$

\section{Subscripts}

amb ambient

$\begin{array}{ll}c & \text { capillary } \\ \text { cond } & \text { condenser } \\ \text { evap } & \text { evaporator } \\ g & \text { gravity } \\ h s & \text { heat source } \\ \text { max } & \text { maximum } \\ l & \text { liquid } \\ v & \text { vapor } \\ w & \text { wick }\end{array}$

\section{REFERENCES}

Açikalin, T., Garimella, S.V., Petroski, J. and Raman, A., 2004. "Optimal design of miniature piezoelectric fans for cooling light emitting diodes," In The Ninth Intersociety Conference on Thermal and Thermomechanical Phenomena In Electronic Systems, 1, 663-671. IEEE. https://doi.org/10.1109/ITHERM.2004.1319239

Choi, J., Jeong, M., Yoo, J. and Seo, M., 2012. "A new CPU cooler design based on an active cooling heatsink combined with heat pipes," Applied thermal engineering, 44, 50-56. https://doi.org/10.1016/i.applthermaleng.2012.03.027

Coleman, H.W. and Steele, W.G., 2018. Experimentation, validation, and uncertainty analysis for engineers. John Wiley \& Sons.

https://doi.org/10.1002/9781119417989

Faghri, A., Heat Pipe Science and Technology. 2016: Global Digital Press.

Hales, A. and Jiang, X., 2018. "A review of piezoelectric fans for low energy cooling of power electronics," Applied Energy, 215, 321-337. https://doi.org/10.1016/j.apenergy.2018.02.014

Han, X., Wang, Y. and Liang, Q., 2018. "Investigation of the thermal performance of a novel flat heat pipe sink with multiple heat sources," International Communications in Heat and Mass Transfer, 94, 71-76.

https://doi.org/10.1016/j.icheatmasstransfer.2018.03.017

Kim, K.S., Won, M.H., Kim, J.W. and Back, B.J., 2003. "Heat pipe cooling technology for desktop PC CPU," Applied thermal engineering, 23(9), 1137-1144. https://doi.org/10.1016/S1359-4311(03)00044-9

Koito, Y., 2019. "Numerical analyses on vapor pressure drop in a centered-wick ultra-thin heat pipe," Frontiers in Heat and Mass Transfer (FHMT), 13.

http://dx.doi.org/10.5098/hmt.13.26

Li, H.Y., Chao, S.M., Chen, J.W. and Yang, J.T., 2013. "Thermal performance of plate-fin heat sinks with piezoelectric cooling fan," International Journal of Heat and Mass Transfer, 57(2), 722-732. https://doi.org/10.1016/j.ijheatmasstransfer.2012.11.005

Li, J., Lin, F., Wang, D. and Tian, W., 2013. "A loop-heat-pipe heat sink with parallel condensers for high-power integrated LED chips," Applied Thermal Engineering, 56(1-2), 18-26. https://doi.org/10.1016/j.applthermaleng.2013.03.016

Li, Y., He, J., He, H., Yan, Y., Zeng, Z. and Li, B., 2015. "Investigation of ultra-thin flattened heat pipes with sintered wick structure," Applied Thermal Engineering, 86, 106-118.

https://doi.org/10.1016/j.applthermaleng.2015.04.027

Liang, T.S. and Hung, Y.M., 2010. "Experimental investigation on the thermal performance and optimization of heat sink with U-shape heat pipes," Energy Conversion and Management, 51(11), 2109-2116. https://doi.org/10.1016/j.enconman.2010.03.003 
Lin, K.T. and Wong, S.C., 2013. "Performance degradation of flattened heat pipes," Applied thermal engineering, 50(1), 46-54.

https://doi.org/10.1016/j.applthermaleng.2012.06.001

Lu, X.Y., Hua, T.C. and Wang, Y.P., 2011. "Thermal analysis of high power LED package with heat pipe heat sink," Microelectronics Journal, 42(11), 1257-1262.

https://doi.org/10.1016/j.mejo.2011.08.009

McGlen, R.J., Jachuck, R. and Lin, S., 2004. "Integrated thermal management techniques for high power electronic devices," Applied thermal engineering, 24(8-9), 1143-1156.

https://doi.org/10.1016/j.applthermaleng.2003.12.029

Mochizuki, M., Saito, Y., Kiyooka, F. and Nguyen, T., 2007. "The way we were and are going on cooling high power processors in the industries," Fujikura Technical Review, 36, 53.

Mochizuki, M., Nguyen, T., Mashiko, K., Saito, Y., Nguyen, T. and Wuttijumnong, V., 2011. "A review of heat pipe application including new opportunities," Frontiers in Heat Pipes (FHP), 2(1), 013001.

https://doi.org/10.5098/FHP.V2.1.3001

Mochizuki, M. and Nguyen, T., 2019. "Review of various thin heat spreader vapor chamber designs, performance, lifetime reliability and application," Frontiers in Heat and Mass Transfer (FHMT), 13. http://dx.doi.org/10.5098/hmt.13.12

Nguyen, T., Mochizuki, M., Mashiko, K., Saito, Y. and Sauciuc, I., 2000. "Use of heat pipe/heat sink for thermal management of high performance CPUS," In Sixteenth Annual IEEE Semiconductor Thermal Measurement and Management Symposium, 76-79. IEEE.

https://doi.org/10.1109/STHERM.2000.837064

Petroski, J., Arik, M. and Gursoy, M., 2009. "Optimization of piezoelectric oscillating fan-cooled heat sinks for electronics cooling," IEEE Transactions on Components and Packaging Technologies, 33(1), 25-31.

https://doi.org/10.1109/TCAPT.2009.2023859
Singh, R., Akbarzadeh, A., Dixon, C., Mochizuki, M. and Riehl, R.R., 2007. "Miniature loop heat pipe with flat evaporator for cooling computer CPU," IEEE transactions on components and packaging technologies, 30(1), 42-49.

https://doi.org/10.1109/TCAPT.2007.892066

Tao, H.Z., Zhang, H., Zhuang, J. and Bowman, W.J., 2008. "Experimental study of heat transfer performance in a flattened AGHP," Applied thermal engineering, 28(14-15), 1699-1710. https://doi.org/10.1016/j.applthermaleng.2007.09.016

Wang, J.C., Huang, H.S. and Chen, S.L., 2007. "Experimental investigations of thermal resistance of a heat sink with horizontal embedded heat pipes," International Communications in Heat and Mass Transfer, 34(8), 958-970. https://doi.org/10.1016/j.icheatmasstransfer.2007.03.015

Xiao, C., Liao, H., Wang, Y., Li, J. and Zhu, W., 2017. "A novel automated heat-pipe cooling device for high-power LEDs," Applied Thermal Engineering, 111, 1320-1329.

https://doi.org/10.1016/j.applthermaleng.2016.10.041

Yoo, J.H., Hong, J.I. and Cao, W., 2000. "Piezoelectric ceramic bimorph coupled to thin metal plate as cooling fan for electronic devices," Sensors and Actuators A: Physical, 79(1), 8-12.

https://doi.org/10.1016/S0924-4247(99)00249-6

Zhou, G., Li, J. and Lv, L., 2016. "An ultra-thin miniature loop heat pipe cooler for mobile electronics," Applied Thermal Engineering, 109, 514523.

https://doi.org/10.1016/j.applthermaleng.2016.08.138

Zhou, W., Xie, P., Li, Y., Yan, Y. and Li, B., 2017. "Thermal performance of ultra-thin flattened heat pipes," Applied Thermal Engineering, 117, 773-781.

https://doi.org/10.1016/j.applthermaleng.2017.01.089 